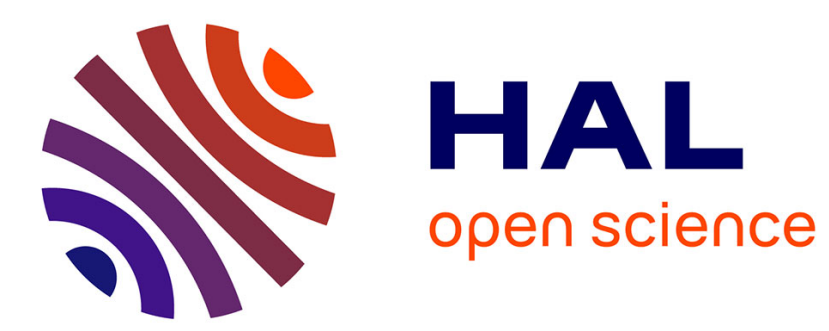

\title{
A micromechanical damage characterization and the modeling of a mineral filled epoxy adhesive
}

\author{
Sébastien Joannès
}

\section{To cite this version:}

Sébastien Joannès. A micromechanical damage characterization and the modeling of a mineral filled epoxy adhesive. Mechanics of Materials, 2014, 75, pp.111-124. 10.1016/j.mechmat.2014.04.009 . hal00509616

\section{HAL Id: hal-00509616}

https://hal-mines-paristech.archives-ouvertes.fr/hal-00509616

Submitted on 26 Jun 2019

HAL is a multi-disciplinary open access archive for the deposit and dissemination of scientific research documents, whether they are published or not. The documents may come from teaching and research institutions in France or abroad, or from public or private research centers.
L'archive ouverte pluridisciplinaire $\mathbf{H A L}$, est destinée au dépôt et à la diffusion de documents scientifiques de niveau recherche, publiés ou non, émanant des établissements d'enseignement et de recherche français ou étrangers, des laboratoires publics ou privés. 


\title{
A micromechanical damage characterization and the modeling of a mineral filled epoxy adhesive
}

\author{
S. Joannès ${ }^{\mathrm{a}, *}$ \\ ${ }^{a}$ Centre des Matériaux, Mines ParisTech, CNRS UMR 7633 \\ BP 87, 91003 Evry Cedex, France
}

\begin{abstract}
Current structural adhesives can be used to assemble a variety of similar and dissimilar materials, usually with minimal surface preparation and sometimes even without degreasing. This kind of performance is obtained by using filled structural polymers which, as a consequence, lead to complex multi-phased composite material microstructures. Nevertheless, the use of mineral fillers such as talc also affects the adhesive mechanical behavior which is of major importance for structural applications. In order to study this type of material, a multi-axial mechanical characterization of an epoxy structural adhesive has been undertaken using a modified Arcan setup. An unfilled and not marketed formulation of the epoxy adhesive has also been tested to emphasize the role of the mineral particles on its mechanical behavior. As a first step, this paper reports the mechanical differences that have been observed between the filled and the unfilled versions of the adhesive, and proposes possible explanations related to microstructural processes. Contribution of the mineral fillers leads to a deterministic failure process. This is suggested, most significantly, by microstructural observations which have revealed useful information concerning the damage evolution and its kinetics. Indeed, the applied mechanical load provokes an exfoliation of talc flakes leading to a pattern of micro-cracks. In a subsequent step in the study, based on both macro and micro experimental results of the adhesive, a damage model has been derived from the vectorial description of cracking modes and its performance has been assessed.
\end{abstract}

Keywords: Adhesive joint, Mineral fillers, Microstructures, Damage mechanics, Mixed mode fracture, Vectorial damage model

\footnotetext{
${ }^{*}$ Corresponding author

Email address: sebastien.joannes@mines-paristech.fr (S. Joannès)

This is the peer reviewed version of the following article: Mechanics of Materials (2014), 75:111-124

which has been published in final form at https://doi.org/10.1016/j.mechmat.2014.04.009 d

This article is made available under the CC-BY-NC-ND 4.0 license, please read the following "author notes"
} 


\section{Author notes 2019}

\section{Licensing}

Copyright (C) 2019. This manuscript version is made available under the

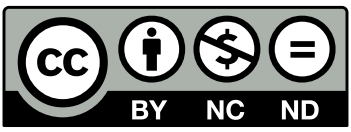

http://creativecommons.org/licenses/by-nc-nd/4.0

You are free to:

- Share copy and redistribute the material in any medium or format as long as you follow the license terms.

Under the following terms:

- Attribution You must give appropriate credit, provide a link to the license, and indicate if changes were made. You may do so in any reasonable manner, but not in any way that suggests the licensor endorses you or your use.

- NonCommercial You may not use the material for commercial purposes.

- NoDerivatives If you remix, transform, or build upon the material, you may not distribute the modified material.

\section{Citation}

Please use the following citation when referencing this work:

15 Joannès, S. (2014). A micromechanical damage characterization and the modeling of a mineral filled epoxy adhesive. Mechanics of Materials, 75:111-124

d. $10.1016 / \mathrm{j}$. mechmat . 2014.04 .009

\section{Correspondence}

Correspondence concerning this article should be addressed to: sebastien.joannes@mines-paristech.fr

or to the address mentioned at:

(1) https://orcid.org/0000-0002-9360-1643 


\section{Introduction}

Design safer, lighter and cleaner cars: this is the challenge to manufacturers and $\mathrm{OEMs}^{1}$ in the twenty-first century. The development of a new vehicle must balance a number of requirements: improve performances in terms of safety and comfort, reduce costs and manufacturing cycle times whilst preserving the environment. In this context, automotive manufacturers and suppliers are increasingly interested in materials previously used for aerospace applications such as magnesium, aluminum and especially organic matrix composites. The overall cost of mono-material solutions, despite some outstanding performances, remains far too high but multi-material designs all have their place for large vehicle series. Prospects for improvement offered by the use of such hybrid structures, however still require the development of specific assembly techniques. Already widely used for windscreen mounting, carrier plastic parts assembly or corrosion protection, high performance adhesives today find more and more applications within the vehicle structure. Adhesive bonding avoids any machining operation and the continuous connection obtained leads to a uniform stress distribution, unlike riveted or bolted joints. In recent years, structural adhesive bonding has therefore become a popular joining method for the transportation industry.

To optimize costs and performances, material suppliers are dealing with multiphased composite material microstructures by providing filled structural adhesives. The addition of mineral fillers to an adhesive compound can modify the viscosity, opacity and weight of the compound but also reduce shrinkage or speed up the crosslink process of the polymer. Other specific functions can be achieved and, for example, the oleophilic nature of talc, which is often seen as a costreducing filler only, makes it popular for minimizing the degreasing operation of metallic surfaces (Greiveldinger et al., 2000). Also hydrophobic, talc can add chemical and water resistance to adhesive products (Mario, 2007). Neverthe-

50 less, the use of mineral fillers will also affect the mechanical behavior of the adhesive (Joannès, 2007; Kulkarni et al., 2009) which is of major importance for structural applications. Alongside advanced material developments, there is a need to gain knowledge about the various effects of the mineral fillers and to propose appropriate material models to describe their behavior. With this

55 perspective, the paper focuses on the case of a commercial single component adhesive, comprising a prepolymer DGEBA type epoxy (Bisphenol A diglycidyl ether) and a DDA (dicyandiamide) crosslinking agent. According to the material supplier, the adhesive formulation is completed by additives and mineral fillers (mass fraction around 23\%) leading to a composite microstructure. In the work described here, an unfilled version of the adhesive (not marketed) has also been used to emphasize the role of the mineral particles on the mechanical behavior.

\footnotetext{
${ }^{1}$ Original Equipment Manufacturer.
} 
The main purpose of this paper is to report the mechanical differences that have been observed between the filled and the unfilled versions of the adhesive, and suggest possible explanations related to microstructural considerations. The

65

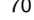

\footnotetext{
${ }^{2}$ Considering that the bulk solidification of the polymer is similar to that obtained in a confined area.

${ }^{3}$ The original test applies to an homogeneous and bulk specimen, but with some modifications, the system was used for adhesive joints (Cognard et al., 2005).
} 
fixture (Arcan, 1978) and is fully described in Joannès (2007). While maintaining the centering quality of the two discs, the design of the Arcan-Mines device allowed the addition of shims to vary the thickness of adhesive joints from 100 to 1500 micrometers. In addition to the Arcan fastening system, the accuracy of the tests was however obviously based on the quality of the specimen. A dedicated assembly mount was thus designed with two steel plates maintaining four substrates which provided for each one a bonding surface of $70 \times 10 \mathrm{~mm}^{2}$. Centering pins and steel shims completed the device for the gluing and was then placed in an oven imposing the cure cycle. Crosslinking of the epoxy adhesive was obtained by imposing a $180^{\circ} \mathrm{C}$ temperature plateau for 60 minutes after a temperature rise rate of $10^{\circ} \mathrm{C} / \mathrm{min}$; the cooling was then carried out at room temperature. The formulation of the commercial adhesive that we denote in this paper by $\beta$ consisted of wollastonite ( $18 \%$ by mass) and talc ( $5 \%$ by mass) silica mineral fillers. The wollastonite was in the form of elongated compact aggregates and the talc in

110 the form of a lamellar structure as is shown below. The unfilled and unmarketed version of $\beta$ is denoted in this paper by $\beta_{N C}$.

Dimensions and proper alignment of each specimen were controlled before the mounting on the Arcan-Mines device. Gripped onto the specimen, a high resolution bi-axial extensometer was used to record the extension and the shear 115 displacement of the "bonded joint"; an assembly composed of the upper substrate, the adhesive joint itself and the lower substrate on an overall thickness (measurement base) of about ten millimeters. An estimation of strains inside the adhesive joint could then be computed by deducting the deformation of the two substrates. Due to the relative stiffness of the substrate (compared to the adhesive), most of the displacement is induced by the adhesive itself: for the considered thicknesses, more than $90 \%$ of the total displacement is induced by the polymer. Applying a loading rate of $70 \mathrm{~N} / \mathrm{s}$, it is thus possible to measure the multiaxial rigidity of the assembly.

\subsection{Mineral filler damage as a direct cause of cohesive failure}

\subsubsection{Experimental results}

First consider aluminum substrates for adhesive joints with a thickness of about $300 \mu \mathrm{m}$ as recommended by the supplier. Thicknesses obtained during the preparation were slightly smaller (about $250 \pm 25 \mu \mathrm{m}$ ). Figure 1 shows tensile and shear quasi-static monotonic results for the filled $\beta$ and unfilled $\beta_{N C}$ formulations. For each test condition, little variability in the results is observed; this reflects the effectiveness of the experimental procedure and the relevance of the Arcan-Mines device for this purpose.

The curves describe the relationship between the load and the elongation of the bonded joints which were both measurable parameters. It will be seen later that, when needed, it was particularly difficult to recover the stress and strain fields 


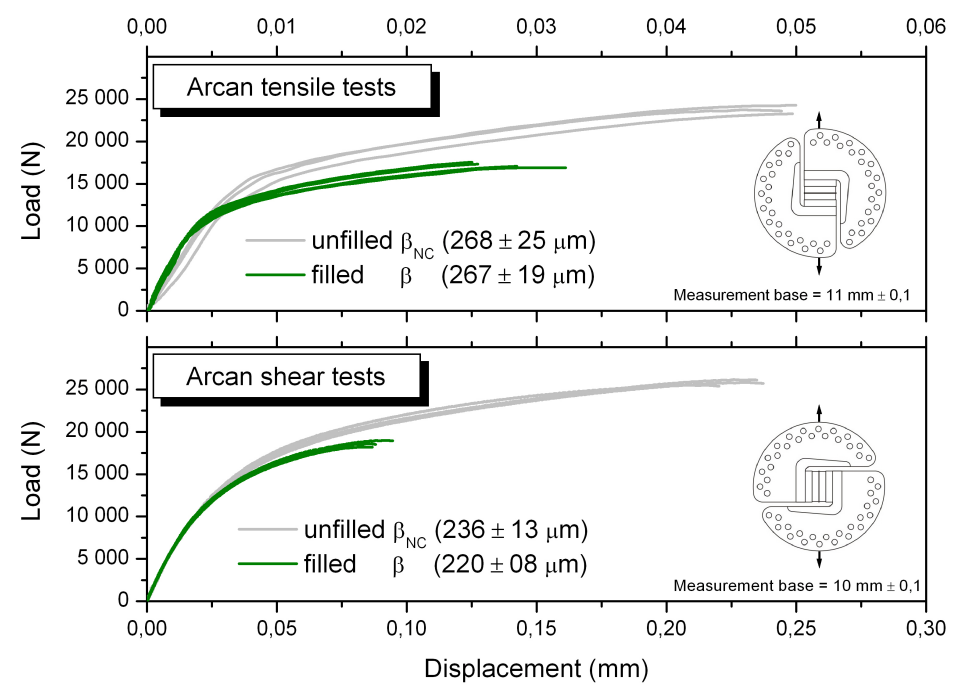

Figure 1: Load-displacement curves of bonded joints obtained for both filled $(\beta)$ and unfilled $\left(\beta_{N C}\right)$ adhesive formulations. Tensile (top) and shear (bottom) Arcan results.

within the adhesive without using a suitable numerical method. However, the load and the elongation were enough to give the first interpretations. It must first be noted that the Arcan-Mines device, coupled to a careful specimen preparation, led to an excellent reproducibility and the dispersion of the curves, condition by condition, was very low. At first sight, the bonded joint stiffnesses seem quite similar between the two formulations and this will be discussed in a following section (§ 2.2.1). Obviously, the two adhesive systems exhibited highly nonlinear behaviors mainly due to the polymer deformation process and this issue will be addressed in separate communications. The main difference between the $\beta$ silica filled formulation and the unfilled adhesive $\beta_{N C}$ was the elongation at break and the failure load which were decreased by the inorganic fillers. Beyond the benefits already mentioned in the introduction for wollastonite and talc, and despite a drop in the mechanical performances, mineral fillers systematically allow a "cohesive" 4 failure within the adhesive to be obtained.

Indeed, pictures in Figure 2 show the failure modes obtained for the two adhesive formulations: on the right, the absence of the polymer on both adherends is symptomatic of an "adhesive failure" whereas on the left, a clear presence of

\footnotetext{
${ }^{4}$ An interfacial failure is commonly described as "adhesive" whereas the failure of the "adhesive material" is termed "cohesive". To avoid confusion, it may be sometimes preferable to use "adhesion failure" and "cohesion failure" expressions (Davis and Bond, 1999).
} 
the adhesive material on the two substrate surfaces characterized a "cohesion failure". When breakage of the substrates outside the joint is not achievable 155 such as with metallic adherends, a cohesion failure mode is generally sought for industrial application. Any adhesion breakage which occurs in service could be a direct result of the manufacturing process such an inadequate surface preparation or a curing problem. A cohesive failure within the adhesive only depends on the adhesive material strength and is thus easier to predict in a design process.

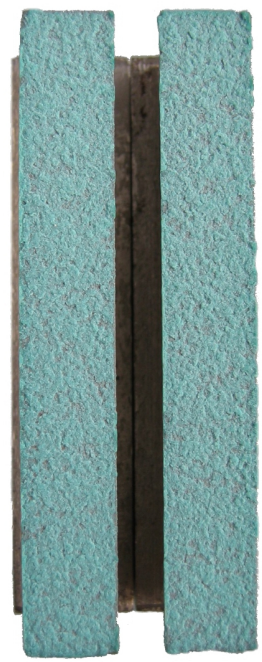

$\beta$

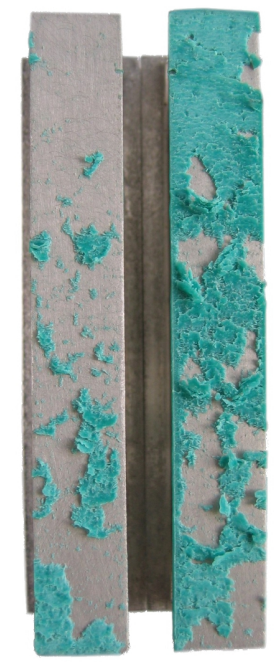

$\beta_{N C}$

Figure 2: Cohesive (left) and adhesive (right) fracture surfaces obtained with respectively the filled $\beta$ and unfilled $\beta_{N C}$ adhesive formulations. Mineral fillers allow a cohesion failure within the polymer to be obtained.

\subsubsection{A deterministic failure threshold}

A previous work with oligocyclic fatigue loads suggested that talc should be the cause of a deterministic failure of the adhesive (Joannès et al., 2010): "the cohesive failure of the adhesive appears at a specific amplitude level, whatever the loading value". In this aforementionned paper, steel adherends were used with $\beta$ adhesive joints of about 250 micrometers. Figure 3 recalls the main results obtained with the Arcan-Mines device in such fatigue loadings. Tensile results are chosen as an example but the same type of behavior was observed with shear loadings. Three cycling conditions are thus presented, showing the evolution of the relative displacement of the bonded joint as a function of time (top) or as a 
170 function of the number of remaining cycles $^{5}$ before failure (bottom). This second graph is particularly instructive since the three curves overlap. It means that the failure occurs when the elongation reaches a quasi-deterministic value of about 9 micrometers.
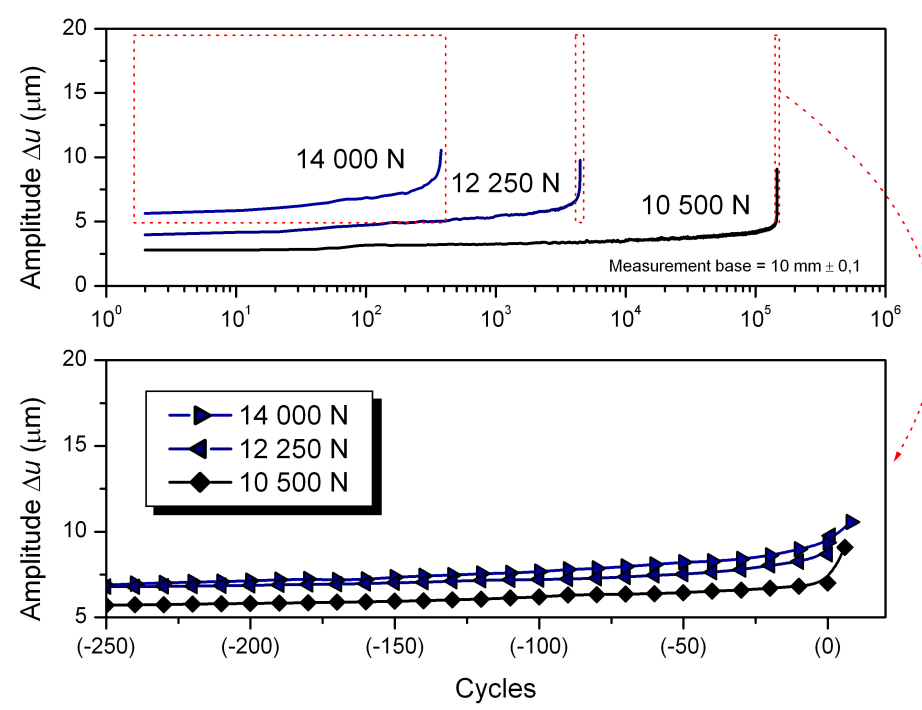

Figure 3: Final evolution of the amplitude of the relative displacement between substrates obtained during oligocyclic tensile tests. The ultimate amplitude is identical whatever the loading level (from Joannès et al. (2010) results).

This is to be related to the quasi-static monotonic result plotted at the top

of Figure 1 where the elongation at break was between 25 and 32 micrometers. As a first approximation, the factor of three between those results corresponds to the ratio between the elastic moduli of the steel and the aluminum substrates. Similar results are obtained with shear loadings: an amplitude of 25 to 30 micrometers at break for cyclic loadings (Joannès et al., 2010) compared to about 80 micrometers

180 (again a factor of three) for monotonic results (at the bottom of Figure 1). This significant experimental result is a key point for industrial designs and helps to build physically motivated material models as described in this paper.

\subsubsection{Microstructural observations of the damage evolution}

The purpose of this section is to clarify the origin of the damage in order to define the constitutive model framework. Essential information about the nature

\footnotetext{
${ }^{5}$ In this aforementioned paper, a damage mechanism was identified by a symptomatically falling rigidity during cycling.
} 
of the damage mechanisms can be obtained by microstructural observations of the adhesive joint. The first microscopic examinations (top left of Figure 4) showed an heterogeneous microstructure with many particles: mainly two types of mineral fillers that have been identified by wavelength dispersive spectroscopy (WDS). $\mathrm{X}$-ray microanalysis allowed therefore the element concentrations for those inclusions to be identified and clearly revealed the wollastonite (calcium silicate) and talc (magnesium silicate).

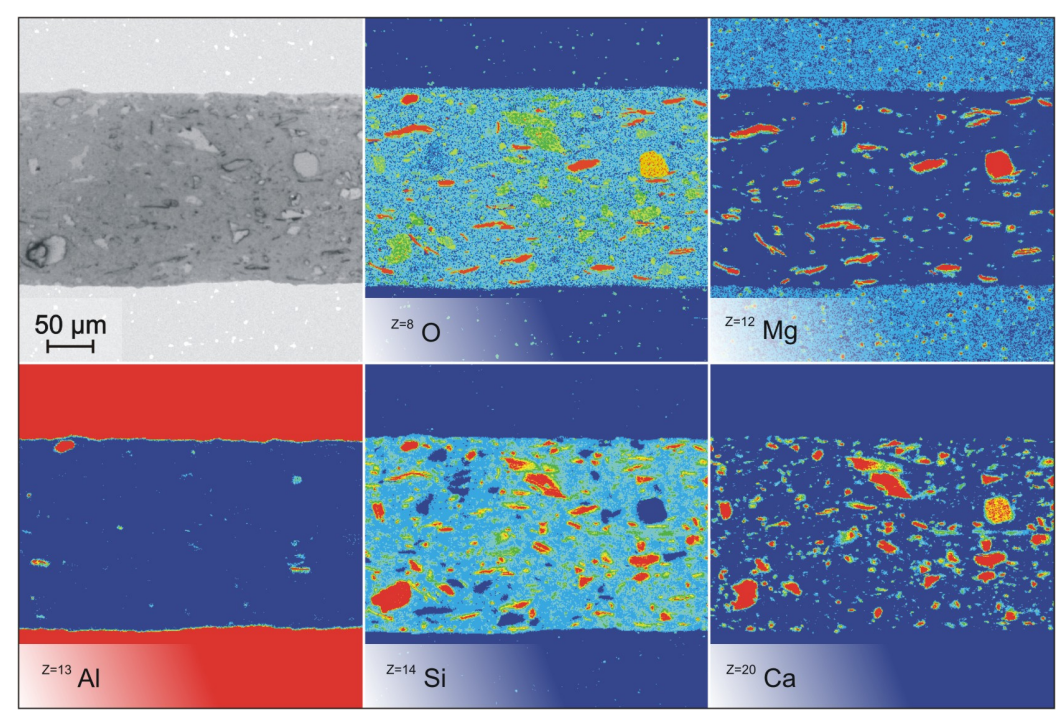

Figure 4: Chemical analysis of an adhesive joint: juxtaposition of an optical imaging and X-ray maps obtained for different elements on a CAMECA SX 100 (Electron Probe Micro Analyzer). The increasing content of elements is indicated by the color from blue to red.

Particle morphology was also quantified by image analysis and brought to light an anisotropy which can contrast the in situ and in bulk controversy as explained comes from the manufacturing process.

To better understand the role that the inclusions may have on the damage kinetics, it would be useful to present their crystallographic characteristics, morphologies and particularly their cleavage properties. Wollastonite, similarly to talc are ordered silicates the basis structure of which is formed by a tetrahedron $\left(\mathrm{SiO}_{4}\right)^{4-}$. Depending on the arrangement of this tetrahedron with positive ions $\left(\mathrm{Ca}^{2+}, \mathrm{Mg}^{2+}\right.$, etc. $)$, the silicate may have a more or less cleavable crystallographic structure. For the wollastonite, a calcium inosilicate mineral, each tetrahedron shares an oxygen atom forming thus a single chain $\left(\mathrm{SiO}_{3}\right)^{2-}$. The calcium layers, in a pseudo-octahedral arrangement, then completes the structure by providing the electrical neutrality of the crystal and linking multiple chains. 
Metallic bonds are less strong than those provided by the sharing of oxygen atoms between the poles of the tetrahedra. This weakness is the origin of the three cleavage planes of wollastonite. Talc is a phyllosilicate, that is to say characterized by lamellar silicate plane sheets (or layers) of tetrahedra. The silicon atoms in the phyllosilicates are thus well organized in a planar hexagonal pattern. The positions available for cations and in particular magnesium are located on top of the layer. The parallel arrangement of these layers induces a perfect basal cleavage. In addition to wollastonite and talc, other types of charges appear in trace amounts (AIMgO, $\mathrm{CaMgO}$, and so on.).

The morphology of inorganic wollastonite fillers (compact elongated aggregates) and talc (flat lamellar structures) promotes their orientation during the manufacture of the adhesive joint. Mechanisms are indeed similar to those found for short fiber composites during injection moulding. During shear flow, the viscosity of the polymer will therefore tend to steer fillers parallel to the flow direction; they undergo a periodic rotating movement and shearing becomes minimal when they are aligned with the flow. This fountain-flow effect was first studied by Tadmor (1974).

It has been suggested in Joannès (2007); Joannès et al. (2010) that the foli225 ated form of talc and its preferential orientation, parallel to the surfaces of the substrates, may explain the deterministic failure threshold highlighted above. Microscale tensile and shear tests were performed under scanning electron microscopy (SEM) and revealed the role of talc particles for the damage kinetics. The possible cleavage of talc flakes, is indeed of major importance in explaining and understanding damage mechanisms in the adhesive studied. In addition to the electronic control unit, this in-house equipment consisted of a small mechanical test machine with a $100 \mathrm{kN}$ load cell capacity and a LVDT transducer. Because of the smallness of the SEM chamber, the specimens were necessarily of reduced dimensions and two configurations have been developed for tensile and shear tests. An asymmetrical geometry of the specimens favored the observation to the detriment of quantitative measurements. A bending mode was indeed introduced in the assembly and maximum stresses were thus localized on the visible surface of the specimen.

SEM images in Figure 5 show the microstructural damage progression in the case of a shear load. The displacement imposed on the specimen was partially absorbed by the sliding of talc sheets. Fillers then opened gradually (exfoliation), forming a network of micro-cracks in which the macrocrack could propagate. On several occasions it was observed that cracks at the interface propagated very quickly, to denser areas of talc in the middle of the adhesive joint. Tensile mechanisms (Joannès, 2007; Joannès et al., 2010) were similar: the deformation was first due to the opening of the mineral fillers which formed islands of microcracks; when the stress level became too high, a macrocrack propagated from place to 

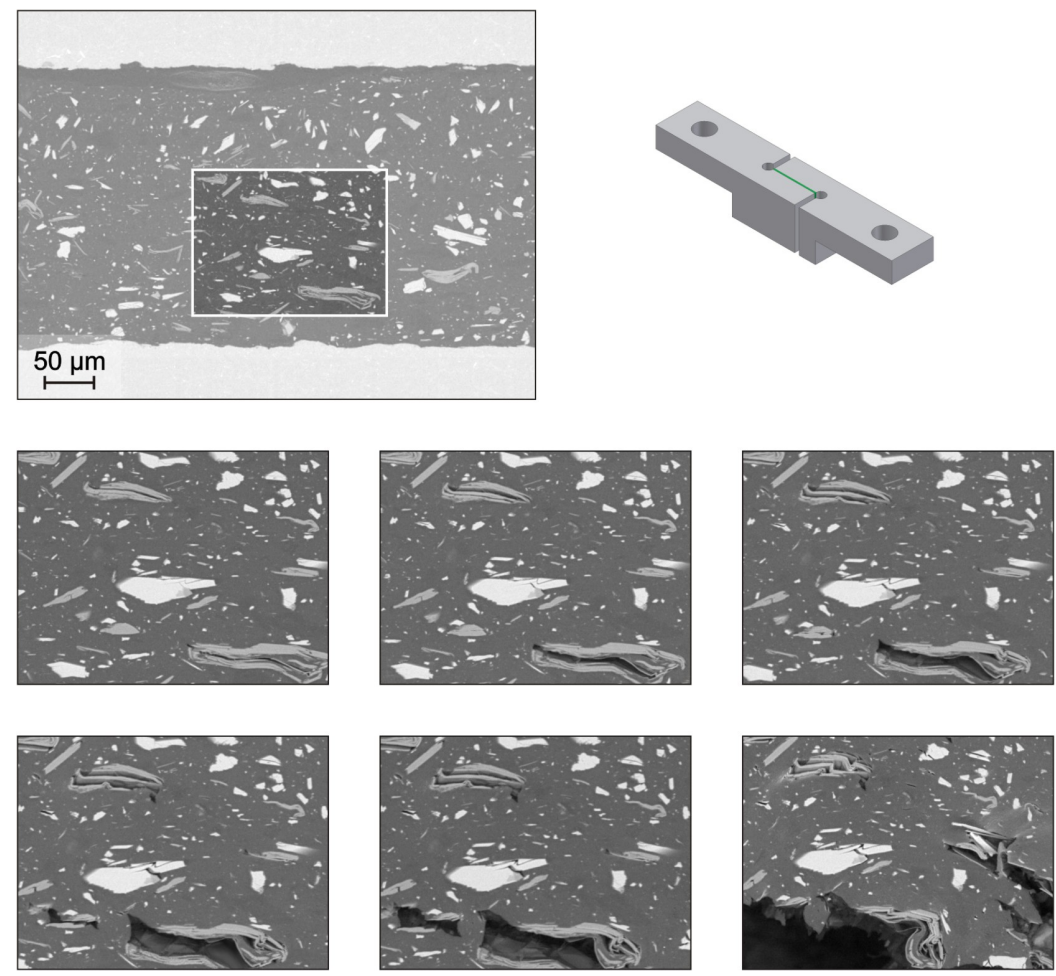

Figure 5: SEM images (backscattered electrons) obtained during an in situ shear test help to visualize the damage mechanisms for increasing loads until failure.

place throughout the joint. These observations explain why the failure of the adhesive joint is always cohesive: while absorbing deformation, talc weakens the joint.

\subsection{Adhesive thickness effects and initial damage}

\subsubsection{Influence of the adhesive thickness on the bonded joint properties}

As mentionned in the introduction, the $\beta$ adhesive formulation considered in this work was not only a laboratory item but finds many industrial applications, especially in the automotive industry. Due to the body assembly tolerances, such applications exploit the gap filling properties of the adhesive thus leading to a bond line thickness variability. For industrial applications, the adhesive thickness is one of the most relevant geometrical parameters mainly because, beyond its influence on the mechanical properties, it has a major economic impact in the case of large productions. Many authors have thus studied the influence of the adhesive thickness on the mechanical properties of bonded joints. At first sight, it may seem appropriate to evaluate the failure strength as a function of thickness 
variations. This is how manufacturers generally provide the peel strength or the shear ${ }^{6}$ strength which nevertheless exhibit opposing results: the overall strength of single lap joints increases as the bond line thickness decreases up to an optimal value, whereas peel strength increases with increasing thicknesses (Kinloch, 1987). Strength results are indeed highly dependent on the loading conditions. As already mentionned, failure strength is not an intrinsic adhesive property and is thus of limited use for design purposes. The failure strength is actually the result of an accumulation of damage that has been highligthed in the previous section. Rather than studying the rupture, changes in the adhesive stiffness is a better way to evaluate thickness effects.

Adhesive joints with thicknesses ranging from 100 to 1500 micrometers were thus analysed using the Arcan-Mines device. To achieve the adhesive behavior it is necessary to remove the contribution of the substrates to the bonded joint rigidity. This step was carried out using a finite element model of the mechanical test able to provide adhesive apparent stiffness ${ }^{7}$ according to the bond line thickness. For both $\beta$ and $\beta_{N C}$ adhesives, results are shown at the top of Figure 6 . These results reveal a significantly drop for shear stiffnesses of the $\beta$ formulation when the adhesive thickness becomes less than 500 micrometers, whereas an only slight decrease is observed for the $\beta_{N C}$ formulation for the lowest thicknesses. These mechanical results have been corroborated by using ultrasonic wave propagation. The attenuation of guided waves indeed reveals information about the properties of the medium. By the measurement of sound velocities it is thus possible to highlight microstructural changes due to thicknesses. The bottom of Figure 6 shows the transverse wave propagation speeds within the adhesives and confirmed, with a better sensitivity, a drop for the $\beta$ formulation and an almost constant velocity for the $\beta_{N C}$ formulation.

Interphase effects where the microstructure of the adhesive can be modified by the proximity of the substrates have been reported for many years (Dillingham and Boerio, 1987; Nigro and Ishida, 1989; Safavi-Ardebili et al., 1997; Roche and Guillemenet, 1999; Bouchet and Roche, 2002; Aufray and Roche, 2008), and are sometimes invoked to justify such stiffness differences for the lowest thicknesses. Nevertheless, such effects exist for both formulations and therefore cannot, by

295 themselves, explain this fall in properties of the $\beta$ adhesive: Mineral fillers are once again at the heart of this issue.

\subsubsection{An initial damage due to the adhesive curing stresses}

Another hypothesis concerns the distribution and orientation of particles that could be influenced by the largest containment of thinner joints. It has been

\footnotetext{
${ }^{6}$ Single lap joint.

${ }^{7}$ Either isotropic or transversly isotropic such in the case of the filled adhesive formulation.
} 

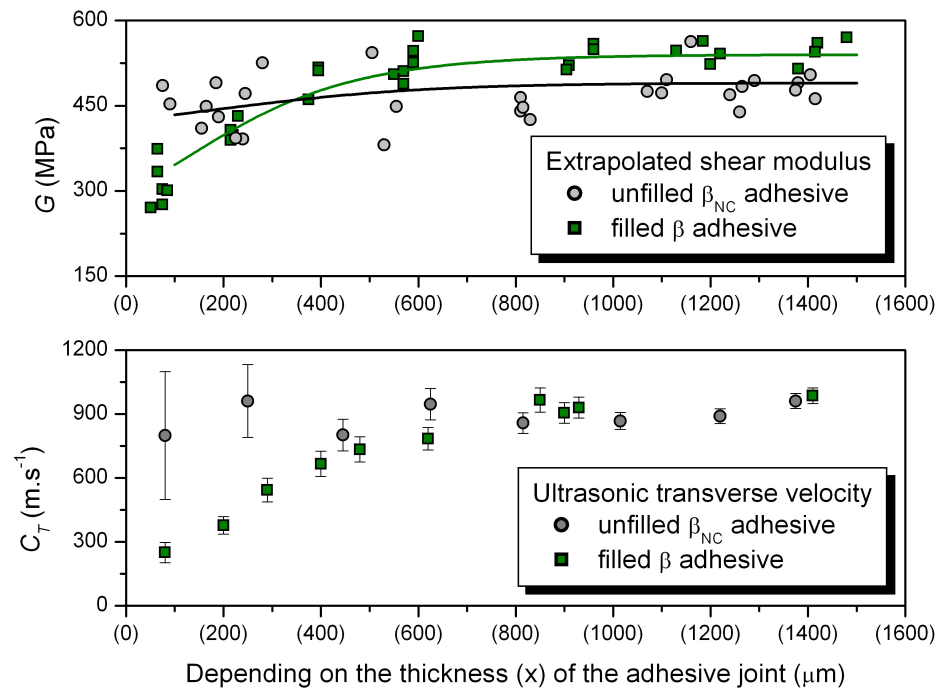

Figure 6: Results as a function of bonded joint thicknesses for both $\beta$ and $\beta_{N C}$ adhesive formulations: Comparison of the shear modulus (top) and the ultrasonic transverse wave velocity within the adhesive (bottom). For thinner joints, the fall in properties of the filled version is clearly visible.

shown that for the considered thicknesses, mineral fillers were oriented parallel to the substrates. Using image analysis for three thicknesses, it has been possible to evaluate the talc orientation tensor. Neither the orientation of fillers nor an interphase effect can explain, by themselves, the differences between the $\beta$ and $\beta_{N C}$ formulations (Joannès, 2007). Ultrasonic wave propagation results, which confirm the trends obtained by mechanical testing, can be compared for an assessment of the damage level within the adhesive. Those results show that for the $\beta$ formulation, an initial damage existed and it was all the more important when the thicknesses were low. The reason for the observed fall in properties seems both related to the presence of mineral fillers and a damage phenomenon occurring during the manufacture of bonded joints. The thermal expansion coefficients of each materials involved for the assembly being different, cooling to room temperature will result in residual stresses. Beyond the simple thermal effect, the chemical crosslinking reaction of the adhesive will probably accentuate the phenomenon. At room temperature, the residual stresses will therefore be localized near the interfaces ${ }^{8}$ and around mineral fillers. Given these microstructural stresses, talc

\footnotetext{
${ }^{8}$ The consequence of residual stresses at the interfaces is sometimes advanced to explain the notion of interphase (Hahn, 1983).
} 
will cleave into thin strips leading to a local damage which will be all the more important as the thicknesses are small and the residual stresses are high.

Unexpectedly, this effect has been seen on the bonded joints used for X-ray microanalysis, since the electron bombardment led to a significant local heating. The specimens having been used for the WDS microanalysis were then observed by a scanning electron microscope. The areas swept by the microprobe are clearly identifiable on the image in Figure 7 . In these areas, talc fillers which were exfoliated, appear white due to cracking of the metallization layer. The talc orientation reinforced this damage effect by promoting the coalescence of the cracks through the polymer.

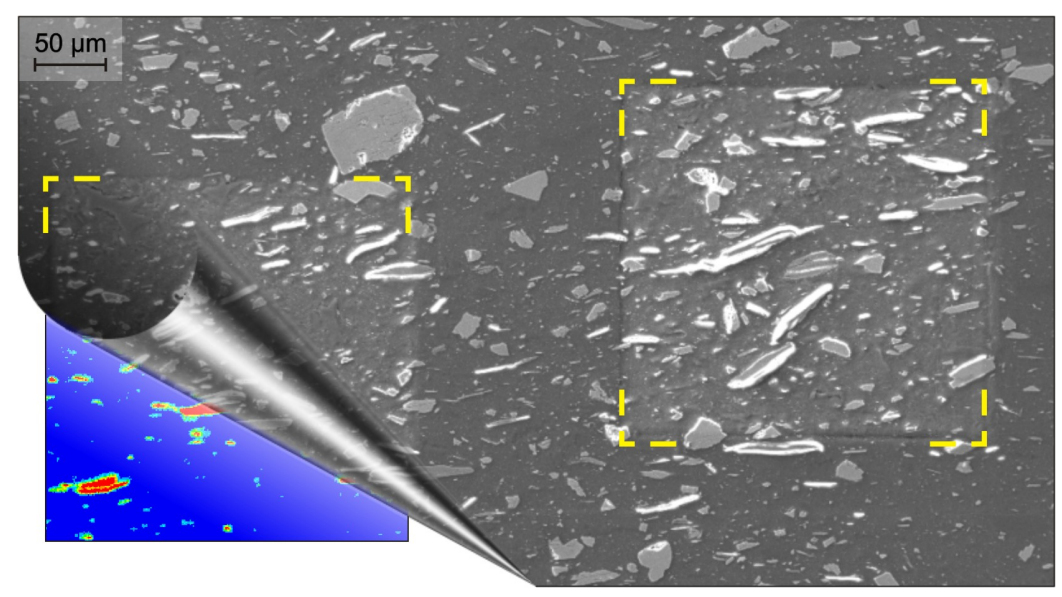

Figure 7: SEM observation of the damage induced by the X-ray microanalysis. Areas that have been scanned and heated by the beam are clearly visible.

\section{From microstructural analysis to damage mechanics}

Looking back over the industrial context mentioned in the introduction, car manufactures require more and more complex assemblies in order to develop new automotive technologies based on light weight designs. In this competitive environment, modelling and simulation that we have stated as industrial goals, now allow engineers to verify the ultimate strength of structures whilst optimizing the materials in accordance with the budget requirements. Simulation codes are not only used for operational conditions calculation but also for investigation of the strength, for both highest monotonic and fatigue loads. If materials are traditionally considered macroscopically homogeneous, the damage process cannot be described properly without taking into account the micromechanical mechanisms. Thus, to assess extreme loading conditions, realistic model-based 
simulations need to physically reflect the triaxial, nonlinear and irreversible material constitutive behavior. Nevertheless, resorting to a microscopic description would be too complex for engineering analysis and damage mechanics (Krajcinovic, 1989) is employed instead.

This section addresses the concept, the design and the implementation ${ }^{9}$ of a damage model dedicated to filled structural adhesives. This approach relies on the identification of the main mechanisms responsible for the failure of the material shown experimentally. It is based on the well known thermodynamics of irreversible processes ${ }^{10}$ framework, which offers a consistent and coherent way to develop constitutive material models. Nevertheless, constitutive behavior models based on this framework have not evolved in the same way for all materials. If the literature is relatively abundant for metals, it is less the case for polymers and even less for adhesives. Many questions remain regarding the modelling of microstructural mechanisms of such materials. In this section, following the model description, a parameter identification procedure is outlined supported by a validation step.

\subsection{The constitutive behavior model}

The experimental work achieved on the adhesive showed that its nonlinear behavior can be attributed to two phenomena: (i) the visco-elasto-plastic deformation of the polymer phase, and (ii) the damage induced by mineral fillers such as the talc exfoliation. The first phenomenon is modeled by a nonlinear kinematic hardening process (Lemaitre and Chaboche, 1985) combined with a modified Drucker-Prager exponent criterion (Joannès, 2007) expressed as Eq. (1), where $f$ describes the yield function separating the elastic domain from the plastic region.

$$
\begin{aligned}
f\left(f_{a}\right)= & \operatorname{sgn}\left(f_{a}\right) \sqrt[a]{\left|f_{a}\right|} \\
f_{a}(\sigma, R, X)= & J^{a}(\alpha-X)-\beta R^{a}(p)+(\beta-1) I_{1}(\alpha-X) R^{a-1}(p) \\
& \text { with } \quad \beta \geq 1, a \geq 1
\end{aligned}
$$

The evolution of the elastic domain is modelled through a scalar variable defining its size $(R)$ and a tensor variable indicating its position $\underset{\sim}{X})$. The evolution of $R$ is governed by the accumulated plastic strain $p . J$ and $I_{1}$ are respectively the Von Mises equivalent stress and the first stress invariant. Finally, $a$ and $\beta$ are model parameters. Full details about this highly hydrostatic sensitive model will be published in a separate communication and this paper is focused on the second phenomenon leading to an anisotropic damage behavior.

\footnotetext{
${ }^{9}$ The model implementation is achieved through the ZebFront $\AA$ preprocessor of the ZeBuLoNß) code (see $\S 3.2$ ).

${ }^{10}$ Built around the concept of the local state and based on a set of internal variables.
} 
According to experimental results reported previously, it can indeed be assumed that the talc oriented exfoliation is responsible for the deterministic failure threshold of the commercial formulation of the adhesive. This damage, initially present within the adhesive joint, evolves very early. The description adopted here therefore makes damageable the elastic part of the behavior model $\left(\varepsilon_{e l} \rightarrow \varepsilon_{e d}\right)$. Within the framework of the continuum damage mechanics, cracks have a size of the order of the material representative volume element in which they grow, and models reflect the consequence of this phenomenon in terms of macroscopic mechanical properties. Generally, damage models use the concept of an internal variable that can be a scalar, a vector or a tensor.

\subsubsection{Internal variables}

The proposed model is based on the vectorial approach suggested by Thionnet and Renard (1993), itself derived from the work of Talreja (1985). This vectorial approach established for composite materials, takes into account the geometry of cracks and the unilateral nature of the damage. Due to the crack closing, this phenomenon results in a stiffness increase when passing from of a tensile stress

385 to a compression stress. In the present method, damage mechanisms are thus modeled by vectors $\underline{V}_{[i]}$ characterizing the intensity and direction of networks ${ }^{11}$ of identical cracks. Each vector $\underline{V}_{[i]}$ actually depends on three scalar variables introducing the concept of loading modes of the fracture mechanics to the damage mechanics. Figure 8 represents a schematic microcracked network, the lips of which are depicted by two parallel planes. Depending on the external mechanical stresses, three cracking regimes can be distinguished: mode 1 corresponds to an opening by lips extension whilst 2 and 3 modes take into account the slip of a lip on the other.

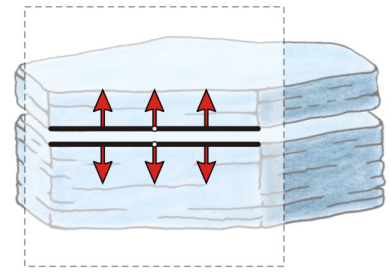

Mode 1

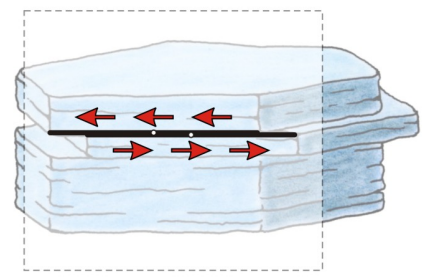

Mode 2

Figure 8: The first two modes of a crack initiation can be represented in the same plane. The third mode appears as an antiplane slip.

\footnotetext{
${ }^{11}$ The $[i]$ notation can take several networks into consideration as we will see later.
} 
Thus, the first internal variable denoted $m_{d[i]}$ characterizes the crack opening mode. The $r_{d[i]}$ variable, complete the geometric information indicating the aperture radius. The combined effects of these two variables result in a continuous evolution of the stiffness tensor during the transition states between tension and compression. Finally, the overall level of damage is quantified through $\alpha_{d[i]}$. Dual variables are respectively denoted $M_{d[i]}, R_{d[i]}$ and $A_{d[i]}$ (Table 1).

\begin{tabular}{cc}
\hline Internal variables & Dual variables \\
\hline$\varepsilon_{e d}$ & $\sigma$ \\
$\alpha_{d[i]}$ & $A_{d[i]}$ \\
$m_{d[i]}$ & $M_{d[i]}$ \\
$r_{d[i]}$ & $R_{d[i]}$ \\
\hline
\end{tabular}

Table 1: State and dual variables needed to model the damage kinetics.

\subsubsection{State potential and dissipation}

The choice of state variables made, it is necessary to write the thermodynamic state potential and the pseudo-dissipative potential from which, respectively, state laws and complementary laws are obtained. These laws, often difficult to formulate, come from scalar functions that can be built according to well-defined rules $^{12}$ The invariant theory provides nevertheless a consistent and methodical framework which results in writing potential functions as polynomial expressions, making it much easier to deduct state and complementary laws. Mathematical notions required for the implementation of the method are not discussed here ${ }^{13}$, but the results are used to build the potential functions of the proposed damage model.

Input data are the set $\mathcal{V}$ of the state variables and the elements of $\mathcal{S}$ representing the material symmetries of the considered medium. It is assumed that $\mathcal{S}$ is a finite subset of $\mathcal{O}(3)$ and is time invariant. The establishment of the potential

\footnotetext{
${ }^{12}$ Respect of material symmetries and objectivity, determinism and local state principles.

${ }^{13}$ For further details see (Thionnet and Martin, 2006).
} 
functions is then based on the following steps:

1. From the components of $\mathcal{V}$ and applying Noether's theorem, it is possible to build an invariant generating family of $\mathcal{V}$ under the influence of $\mathcal{S}$.

2. According to the desired modelling fineness, the most general polynomial consisting of the elements previously identified and by setting conditions on the partial and total degrees can be built.

3. The objectivity of the model is provided by the tensoriality of the polynomial coefficients.

The state variables can be summarized by the strain tensor $\varepsilon_{e d}$ and vectors $\underline{V}_{[i]}\left(\alpha_{d[i]}, m_{d[i]}, r_{d[i]}\right)$ that model the internal cracking phenomena. To simplify the problem, it is assumed that the damage of each network is independent of the others. This results mathematically by the fact that the evolution of the vector $\underline{V}_{[i]}$ is decoupled from those of the vectors $\underline{V}_{[j], j \neq i}$. Input data is thus the set $\mathcal{V}=\left\{\varepsilon_{e d}, \underline{V}\right\}$, the $\underline{V}$ vector representing, in any desired manner, one of the microcracks network. All components of $\mathcal{V}$ are given in a direct orthonormal basis $\left(\underline{x}_{1}, \underline{x}_{2}, \underline{x}_{3}\right)(2)$.

$$
\underline{\varepsilon}_{e d}=\left(\begin{array}{lll}
\varepsilon_{e d, 11} & \varepsilon_{e d, 12} & \varepsilon_{e d, 13} \\
\varepsilon_{e d, 12} & \varepsilon_{e d, 22} & \varepsilon_{e d, 23} \\
\varepsilon_{e d, 13} & \varepsilon_{e d, 23} & \varepsilon_{e d, 33}
\end{array}\right) \quad \underline{V}=\left(\begin{array}{c}
V_{1} \\
V_{2} \\
V_{3}
\end{array}\right)
$$

To define the group of symmetries of the adhesive, the talc is assimilated to a regular hexagonal prism with axis $\underline{x}_{3}$ (Figure 9). In this configuration, it is assumed that the decoupled evolution of three microcrack networks is able to account for the transverse isotropic nature of the material. Accordingly, three local coordinate systems are defined with an $\underline{x}_{3}$ axis of rotation and $0, \pi / 3$ and $2 \pi / 3$ angles.

It is also considered that the deformation of each microcracks network can be represented by the first and second local modes; the third mode of the network $[i]$ becomes a second mode for the networks $[j], j \neq i$. For each coordinate system, the $\underline{V}$ vector can be expressed only with its normal (in the $\underline{x}_{3[i]}$ direction, denoted $V_{N}$ ) and tangential (in the $\underline{x}_{1[i]}$ direction, denoted $V_{T}$ ) components. Similarly, the strain tensor can be limited to its plane components $\varepsilon_{e d, 11}, \varepsilon_{e d, 13}$ and $\varepsilon_{e d, 33}$. Orthogonal transformations that leave invariant the local description of this damage geometry are the identity $I$ and the $R_{2[i]}$ rotation, forming the 

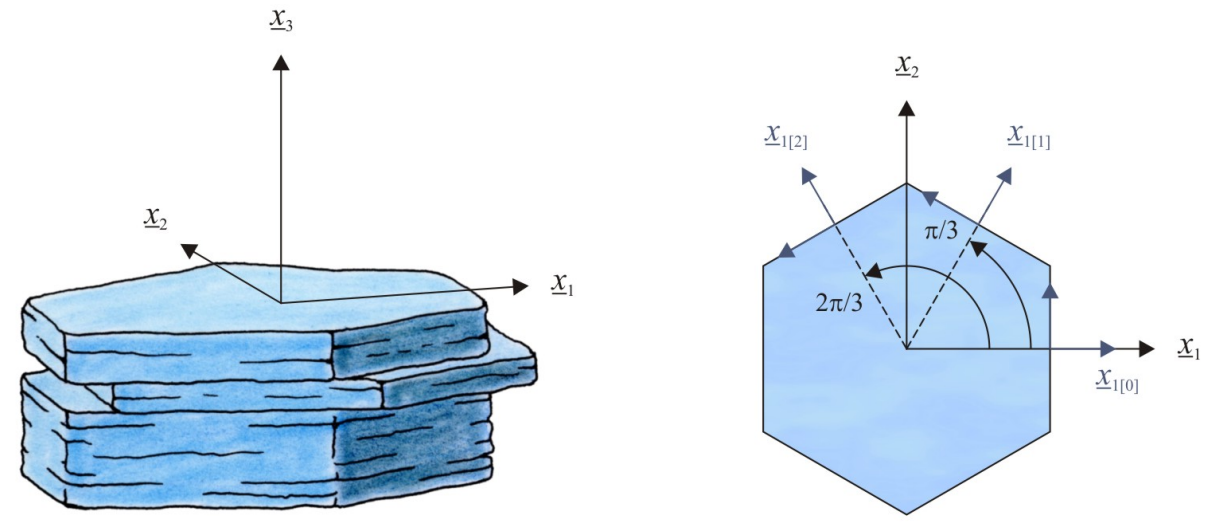

Figure 9: The talc is represented by a regular hexagonal prism. Sliding systems are described by the first and second local modes in the plane $\left(\underline{x}_{1[i]}, \underline{x}_{3[i]}\right)$.

group of material symmetries $\mathcal{S}(3)$.

$$
\mathcal{S}=\left\{I, R_{2[i]}\right\}, \quad I=\left(\begin{array}{ccc}
1 & 0 & 0 \\
0 & 1 & 0 \\
0 & 0 & 1
\end{array}\right), \quad R_{2[i]}=\left(\begin{array}{ccc}
1 & 0 & 0 \\
0 & -1 & 0 \\
0 & 0 & 1
\end{array}\right)
$$

445

For physical considerations, the free energy function is written as an $\mathcal{S}$ invariant polynomial of partial degrees 0 or 2 with respect to the components of $\varepsilon_{e d}$ and $\underline{V}$. The application of the three steps of the invariants theory aforementioned leads to the writing of the free energy according to Eq. (4), where $P_{20}, P_{02}$ and $P_{22}$ are the most general polynomials that satisfy the stated requirements.

$$
\psi_{e d}\left(\varepsilon_{e d}, \underline{V}\right)=P_{20}\left(\varepsilon_{e d}\right)+P_{02}(\underline{V})+P_{22}\left(\varepsilon_{e d}, \underline{V}\right)
$$

The third step of the method is used to formulate $P_{20}$ depending on the $C_{0}$ tensor characterizing the stiffness of a virgin material without any damage. Similarly, $P_{22}$ can be expressed in terms of three behavior tensors: $\underset{\sim}{C_{N}}, \underset{\sim}{C_{T}}$ and $\underset{\sim}{C_{N T}}$. Considering that there is not stored energy when the crack is closed ${ }^{14}$, the polynomial $P_{02}$ could be set to zero. Finally, according to Eqs. (5) and (6), the 455 components of $\underline{V}\left(V_{N}\right.$ et $\left.V_{T}\right)$ are expressed in terms of normal $U_{N}\left(m_{d}, r_{d}\right)$ and

${ }^{14}$ This is equivalent considering that no inclusion can prevent a crack from closing completely. 
tangential $U_{T}\left(m_{d}, r_{d}\right)$ displacements of the crack lips and are based on a function $f_{d}: \alpha_{d} \mapsto f_{d}\left(\alpha_{d}\right)$ for taking into account the damage level.

$$
\begin{aligned}
& V_{N}\left(\alpha_{d}, m_{d}, r_{d}\right)=f_{d}\left(\alpha_{d}\right) U_{N}\left(m_{d}, r_{d}\right) \\
& V_{T}\left(\alpha_{d}, m_{d}, r_{d}\right)=f_{d}\left(\alpha_{d}\right) U_{T}\left(m_{d}, r_{d}\right)
\end{aligned}
$$

Within the framework of the damageable elasticity under consideration we can write $\psi_{e d}$ as Eq. (7).

$$
\begin{aligned}
\rho \psi_{e d}\left(\varepsilon_{e d}, \underline{V}\left(\alpha_{d}, m_{d}, r_{d}\right)\right) & =\frac{1}{2} \varepsilon_{e d}: \underset{\sim}{C}\left(\alpha_{d}, m_{d}, r_{d}\right): \varepsilon_{e d} \\
\underset{\sim}{C}\left(\alpha_{d}, m_{d}, r_{d}\right) & =\underset{\sim}{C_{0}}-f_{d}^{2}\left(\alpha_{d}\right) \underset{\sim}{C_{d}}\left(m_{d}, r_{d}\right) \\
\underset{\approx}{C_{d}}\left(m_{d}, r_{d}\right) & =\underset{\sim}{\underset{\sim}{C}} U_{T}^{2}\left(m_{d}, r_{d}\right) \cdots \\
\cdots & +\underset{\sim}{C_{N}} U_{N}^{2}\left(m_{d}, r_{d}\right) \cdots \\
\cdots & +\underset{\sim}{C_{N T}} U_{N}^{2}\left(m_{d}, r_{d}\right) U_{T}^{2}\left(m_{d}, r_{d}\right)
\end{aligned}
$$

460 From a mathematical point of view, $\psi_{e d}$ replaces $\psi_{e l}$ in the partition of the thermodynamic potential $\psi$. The state laws specific to the damagable part are given by the relations $(8)$ to $(11)$ where $\underset{\sim}{C}$ denotes the stiffness tensor affected by the damage. .

$$
\begin{aligned}
\sigma & =\rho \frac{\partial \psi}{\partial \varepsilon_{e d}}=\underset{\sim}{\underset{\sim}{C}}\left(\alpha_{d}, m_{d}, r_{d}\right): \underline{\varepsilon}_{e d} \\
A_{d} & =\rho \frac{\partial \psi}{\partial \alpha_{d}}=\frac{1}{2}{\underset{\varepsilon}{e d}}_{e}:\left[-\frac{\partial f_{d}^{2}\left(\alpha_{d}\right)}{\partial \alpha_{d}} \underset{\sim}{\underset{\sim}{C}}\left(m_{d}, r_{d}\right)\right]: \varepsilon_{e d} \\
M_{d} & =\rho \frac{\partial \psi}{\partial m_{d}} \\
R_{d} & =\rho \frac{\partial \psi}{\partial r_{d}}
\end{aligned}
$$

It is also assumed that when the cracks are closed, the friction between their lips is nonexistent. $m_{d}$ and $r_{d}$ are thus non dissipative variables and this means that $M_{d}=0$ and $R_{d}=0$. Applying the implicit function theorem leads to:

- $m_{d}=m_{d}\left(\varepsilon_{e d}, \alpha_{d}\right)$

- $r_{d}=r_{d}\left(\varepsilon_{e d}, \alpha_{d}\right)$

$f_{d}\left(\alpha_{d}\right)$ reflects the damage level and smooths the loss of stiffness with respect to $\alpha_{d}$. It is an increasing function defined by Eq. (12) and when the material is 
intact (i.e. $\alpha_{d}=0$ ), there is no stiffness loss.

$$
f_{d}^{2}\left(\alpha_{d}\right)=\frac{\alpha_{d}}{1+\alpha_{d}}
$$

To determine the form of $m_{d}$ and $r_{d}$ functions, it is of course possible to use a local description of the characteristic microscopic crack by "measuring" the geometric parameters. But more simply, it is possible to just consider $m_{d}$ and $r_{d}$ as scalar functions macroscopically defining the mode and the opening radius of the crack. For a given value of the damage, $m_{d}$ must be a continuous function with values between 1 and 2 and $r_{d}$ a continuous and positive function (13). $m_{d}$ is thus equal to 1 if $\varepsilon_{13}=0$, equal to 2 if $\varepsilon_{33}=0$ and for mixed modes, $m_{d}$ takes intermediate values. In Eq. (13), the scalar variable $q$ is introduced as the ratio between $\varepsilon_{33[R]}$ and $\varepsilon_{13[R]}$ which are respectively the tensile and the shear failure strains.

\begin{tabular}{c|c|c}
\cline { 2 - 3 } & $\varepsilon_{33}>0$ & $\varepsilon_{33} \leq 0$ \\
\hline$m_{d}$ & $\frac{2 \varepsilon_{13}^{2}+\frac{\varepsilon_{33}^{2}}{q^{2}}}{}$ & \\
& $\varepsilon_{13}^{2}+\frac{\varepsilon_{33}^{2}}{q^{2}}$ & \\
\hline$r_{d}$ & $\sqrt{\varepsilon_{33}^{2}+\varepsilon_{13}^{2}}$ & $\sqrt{\varepsilon_{13}^{2}}$ \\
\hline
\end{tabular}

In the case of a zero strain state, the displacement jumps $U_{N}$ and $U_{T}$ must vanish according to the relations (14) and (15).

$$
\begin{aligned}
& \forall m_{d}, \quad U_{N}\left(m_{d}, r_{d}=0\right)=0 \\
& \forall m_{d}, \quad U_{T}\left(m_{d}, r_{d}=0\right)=0
\end{aligned}
$$

While opening the characteristic crack in mode 1 or 2 , the vector modelling the damage must have a unique normal or tangential component. This imposes the relations (16) and (17).

$$
\begin{array}{ll}
\forall r_{d}, & U_{N}\left(m_{d}=1, r_{d}\right)=0 \\
\forall r_{d}, & U_{T}\left(m_{d}=2, r_{d}\right)=0
\end{array}
$$

To ensure a gradual restoration of the material properties between tension and compression loads, the influence of $m_{d}$ and $r_{d}$ parameters is limited. An exponential form is thus used with an attenuation parameter $\vartheta_{d}$ leading to the 490 relations (18) and (19).

$$
\begin{aligned}
& U_{N}=\left(1-\mathrm{e}^{-\vartheta_{d}\left(2-m_{d}\right)}\right)\left(1-\mathrm{e}^{-\vartheta_{d} r_{d}}\right) \\
& U_{T}=\left(1-\mathrm{e}^{-\vartheta_{d}\left(m_{d}-1\right)}\right)\left(1-\mathrm{e}^{-\vartheta_{d} r_{d}}\right) \\
& 21
\end{aligned}
$$


Laws of State are clarified and it is now necessary to establish the complementary laws related to the dissipative processes. The evolution of the damage variable $^{15} \alpha_{d}$ must respect the Clausius-Duhem inequality summarizes in (20).

$$
-A_{d} \dot{\alpha_{d}} \geq 0 \quad \forall \dot{\alpha_{d}}
$$

Taking into account the previous inequality, the damage phenomenon is assumed 495 to be independent of time (no viscosity effect) and the evolution of the variable $\alpha_{d}$ may be written assuming the existence of a threshold function $g$. This function is associated with a convex criterion as for $g\left(\varepsilon_{e d}, \alpha_{d}, m_{d}, r_{d}\right) \leq 0$, the material does not undergo any damage. The complementary law can thus be written according to Eq. (21) where $g$ is defined by Eq. (22). $y_{1}$ and $y_{2}$ define the minimum and maximum of the sigmoid curve used as a damage threshold. $\alpha_{d 0}$ and $\Delta_{d}$ allow to fix the position of the inflection point and the slope of the curve at that point.

$$
\begin{gathered}
\dot{\alpha}_{d}=-\dot{\lambda}_{d} \frac{\partial g}{\partial A_{d}} \\
g\left(\varepsilon_{e d}, \alpha_{d}, m_{d}, r_{d}\right)=A_{d}-A_{d 0} \quad \text { with } \quad A_{d 0}=y_{2}+\frac{y_{1}-y_{2}}{1+\mathrm{e}^{\left(\alpha_{d}-\alpha_{d 0}\right) / \Delta_{d}}}
\end{gathered}
$$

Determining the damage multiplier $\dot{\lambda}_{d}$ goes through writing the consistency condition $\dot{g}=0$ (23).

$$
\begin{aligned}
\dot{g} & =\frac{\partial g}{\partial \varepsilon_{e d}}: \dot{\varepsilon}_{e d}+\frac{\partial g}{\partial \alpha_{d}} \dot{\alpha}_{d}+\underbrace{\frac{\partial g}{\partial m_{d}} \dot{m}_{d}+\frac{\partial g}{\partial r_{d}} \dot{r}_{d}}_{\text {nodissipation } \rightarrow 0} \\
& =\frac{\partial A_{d}}{\partial \varepsilon_{e d}}: \dot{\varepsilon}_{e d}-\dot{\lambda}_{d}\left(\frac{\partial A_{d}}{\partial \alpha_{d}}-\frac{\partial A_{d 0}}{\partial \alpha_{d}}\right)
\end{aligned}
$$

Finally, the Laws of State concerning the $A_{d}$ variable (9) allow the partial derivatives Eqs. (24) and (25) to be expressed as a function of $\psi$ resulting in $\dot{\lambda}_{d}(26)$.

$$
\begin{aligned}
\frac{\partial A_{d}}{\partial \varepsilon_{e d}} & =\rho \frac{\partial^{2} \psi}{\partial \varepsilon_{e d} \partial \alpha_{d}} \\
\frac{\partial A_{d}}{\partial \alpha_{d}} & =\rho \frac{\partial^{2} \psi}{\partial \alpha_{d}^{2}}
\end{aligned}
$$

\footnotetext{
${ }^{15}$ The $m_{d}$ and $r_{d}$ variables are not dissipative and only the evolution of $\alpha_{d}$ must be defined.
} 


$$
\dot{\lambda}_{d}=\frac{\rho \frac{\partial^{2} \psi}{\partial \varepsilon_{e d} \partial \alpha_{d}}: \dot{\varepsilon}_{e d}}{\rho \frac{\partial^{2} \psi}{\partial \alpha_{d}^{2}}-\frac{\partial A_{d 0}}{\partial \alpha_{d}}}
$$

\subsection{Model implementation, parameters identification and validation case}

The physically based constitutive behavior model proposed in this paper has been implemented and tested using the Z-set $\AA^{16}$ suite computing solution. The Z-set $\AA$ package includes, amongst others, the Z-mat $\AA$ material constitutive model library, and a full-featured general purpose finite element solver called ZeBuLoN@. Z-mat $\AA$ can moreover be used as a material library plugin for major finite element solvers. In addition to a large base of non-linear constitutive models, Z-mat $\AA$ provides the ZebFront $\AA$ environment that has been used for developing the proposed damage model. The object-oriented programming 515 of the Z-set@ products give them a high degree of flexibility and modularity. ZebFront $\AA$ is indeed provided with dedicated and robust integration methods which directly manipulates mechanical objects and algebra. The explicit RungeKutta algorithm has been chosen for its simplicity and the constitutive relations have been formulated naturally as scalar, vector or tensor forms such as described in the previous section.

Following the model implementation, it is necessary to identify the model coefficients. For that purpose, reverse engineering has been adopted by using the Z-opt $\AA$ optimization package. Experimental tests carried out on the ArcanMines device were simulated numerically using a suitable mesh. Figure 10 shows the model of the experimental set-up with a detail of the mesh in the bonded joint area. The mesh is also strongly densified on each side of the median plane to allow a digital recovery of the load-displacement curve in a local coordinate frame, corresponding to the experimental measurement (same displacement base).

Given an initial set of parameters, Z-opt $\AA$ computed the least-square distance

530 between experiments and simulations and provided an updated set of parameters using the Levenberg-Marquardt gradient method chosen. Full details about such a numerical identification step are given in Joannès (2007) and the result of the parameters identification is shown in Figure 11.

For both loading conditions, simulated curves perfectly reproduce the experimental results. Some drawbacks might nevertheless be mentioned. The simplicity of the explicit implementation suffers from a poor convergence performance which resulted in excessive time for calculations. The simulations were thus stopped

\footnotetext{
${ }^{16}$ http://zset-software.com/
} 


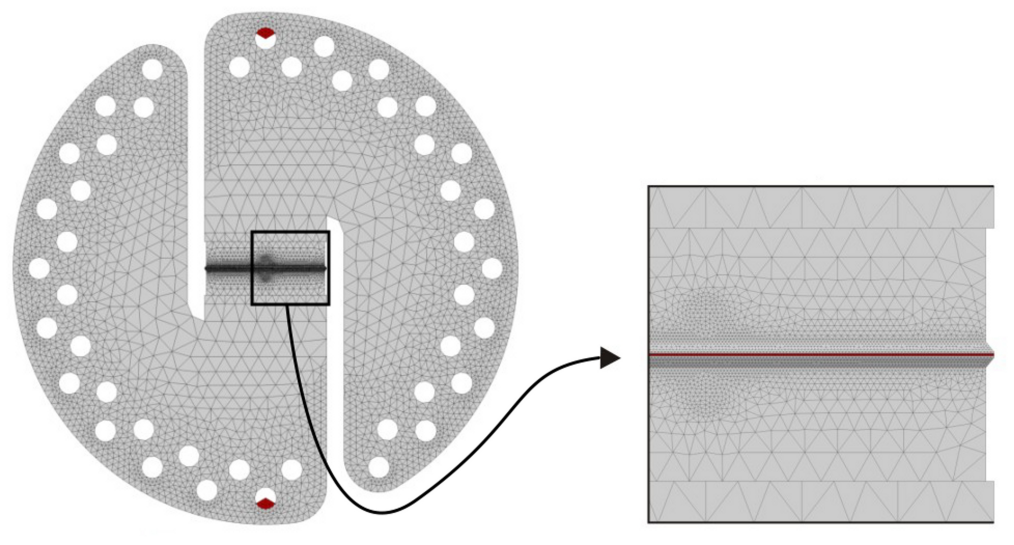

Figure 10: Assembly of the 3D mesh model of the Arcan-Mines device. The refined mesh in the bonded joint area is picking up the local displacement field to be compared to the high resolution extensometer experimental results.

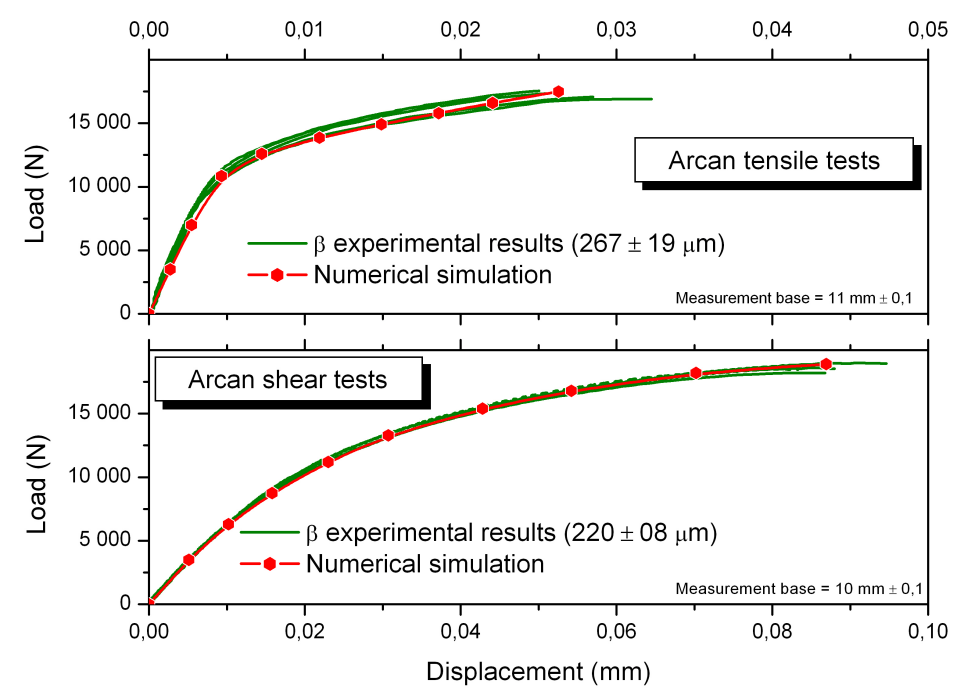

Figure 11: Identification results of the $\beta$ adhesive behavior in tension (top) and shear (bottom) with the Arcan-Mines set-up. 
before the full damage of the adhesive material which led to a zero stiffness associated to an unattainable computation. This convergence issue can certainly be removed by using a more robust and dedicated algorithm which is not in the scope of this paper. However, this more difficult convergence at the end of the calculation artificially results in a "significant" damage reflecting the imminent break of the joint and the transition between damage and fracture mechanics. Moreover, from an engineering point of view, the prediction of an imminent break is generally sufficient.

Following the identification step, an assessment of the accuracy of the model is needed for more complex loads. For that purpose, some experimental results on bonded cylinder specimens ${ }^{17}$ are used (Mario, 2007; Joannès, 2007). By constraining the cylinder translation, this geometry allows a mixed mode loading of the adhesive joint and the adhesive are thus subjected to both shear and tensile stresses. This configuration is relatively simply instrumented and modeled. An angular velocity of $10^{-4}$ rad.s ${ }^{-1}$ is imposed and the resulting torque is measured by strain gauges. A linear displacement transducer is also used to evaluate the twist angle in the vicinity of the adhesive joint. A comparison between experimental results and a numerical simulation is given inFigure 12. At first sight, the experimental scatter is higher than that obtained by the Arcan-Mines device, thus validating the relevance of the Arcan method for an accurate characterization. This scatter is probably due to slight alignment problems or joint thicknesses issues. Nevertheless, a good correlation is obtained and the model faithfully reproduces the stiffness response of the bonded assembly. Finally, the end of the computation fits well with the maximum load allowed by the system, thus validating the proposed approach.

\section{Conclusion}

An experimental study of the mechanical behavior and the failure mechanisms of an epoxy structural adhesive has been performed. A specific set-up has been used to characterize the bonded joint stiffnesses both in tension and shear with high reproducibility and variable adhesive thicknesses ranging from 100 to 1500 micrometers. As a first objective, both filled and unfilled (not marketed) versions of the adhesive have been tested in order to illustrate the mechanical differences due to the mineral fillers. Thanks to micromechanical analysis, it has been possible to identify the probable causes of "thickness effects" and the deterministic cohesive failure shown experimentally. Indeed, the foliated form of talc and its preferential orientation, parallel to the surfaces of the substrates, is at the

${ }^{17} \varnothing 20 \mathrm{~mm}$ with a length of $2 \times 40 \mathrm{~mm}$ 


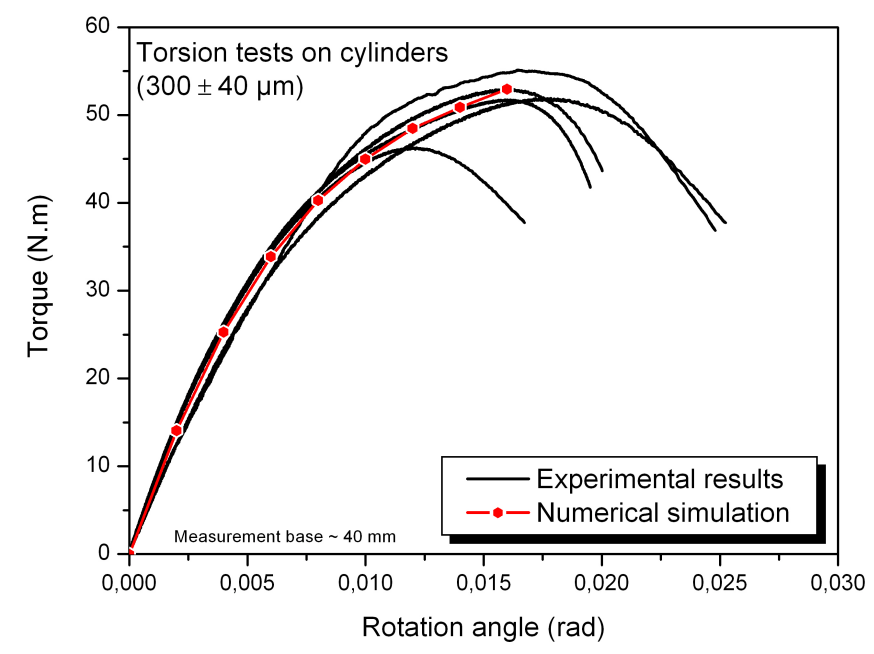

Figure 12: Good fit between the simulation of a cylinder torsion test and experimental results.

root of an initial anisotropic damage which results in a cohesive failure within the adhesive.

Based on both macro and micro experimental results, a physically based damage model has been proposed. This model is derived from the vectorial description of cracking modes and is able to describe the filled adhesive damage kinetics. Reverse engineering allowed the model parameters to be identified and a finite element simulation of a cylinder torsion test has validated the presented approach. The model, though deterministic in nature, can easily incorporate statistical effects thus providing an efficient tool fo adhesive bonded designs.

\section{References}

Arcan, M. (1978). A method to produce uniform plane-stress states with applications to fiberreinforced materials. Experimental Mechanics, 18(4):141-146.

Aufray, M. and Roche, A. A. (2008). Is gold always chemically passive?: Study and comparison of the epoxy-amine/metals interphases. Applied Surface Science, 254(7):1936-1941.

Bouchet, J. and Roche, A. A. (2002). The formation of epoxy/metal interphases : mechanisms and their role in practical adhesion. The Journal of Adhesion, 78(9):799-830.

590 Cognard, J. Y., Davies, P., and Sohier, L. (2005). Development of an improved adhesive test method for composite assembly design. Composites Science and Technology, 65(3-4):359-268.

Davis, M. and Bond, D. (1999). The Importance of Failure Mode Identification in Adhesive Bonded Aircraft Structures and Repairs. In Proceedings of the 12th. International Conference on Composite Materials. 
Dean, G. D., Duncan, B. C., Adams, R., Thomas, R., and Vaughn, L. (1996). Comparison of Bulk and Joint Specimen Tests for Determining the Shear Properties of Adhesives. Technical Report CMMT(B)51, National Physical Laboratory, UK.

Dillingham, R. G. and Boerio, F. G. (1987). Interphase composition in aluminum/epoxy adhesive joints. The Journal of Adhesion, 24(2-4):315-335.

600 Greiveldinger, M., Jacquet, D., Verchere, D., and Shanahan, M. E. R. (2000). Collage de substrats huils : Devenir et influence de l'huile sur la formation d'une interphase. Annales de chimie, 25(3):211-224.

Hahn, H. T. (1983). Residual stresses in polymer matrix composite laminates. Journal of Composite Materials, 10(4):266-278.

605 Joannès, S. (2007). Caractérisation mécanique et outil d'aide au dimensionnement des collages structuraux. PhD thesis, Mines-ParisTech, France.

Joannès, S. (2014). A micromechanical damage characterization and the modeling of a mineral filled epoxy adhesive. Mechanics of Materials, 75:111-124.

Joannès, S., Renard, J., and Gantchenko, V. (2010). The role of talc particles in a structural adhesive submitted to fatigue loadings. International Journal of Fatigue, 32(1):66-71.

Kinloch, A. J. (1987). Adhesion and Adhesives. Chapman and Hall.

Krajcinovic, D. (1989). Damage mechanics. Mechanics of Materials, 8(2-3):117-197.

Kulkarni, M. G., Geubelle, P. H., and Matouš, K. (2009). Multi-scale modeling of heterogeneous adhesives: Effect of particle decohesion. Mechanics of Materials, 41(5):573-583.

615 Lemaitre, J. and Chaboche, J. L. (1985). Mcanique des matriaux solides. Dunod.

Lilleheden, L. (1994). Mechanical properties of adhesives in situ and in bulk. International Journal of Adhesion and Adhesives, 14(1):31-37.

Mario, O. (2007). Etude du vieillissement des assemblages structuraux acier/aluminium : influence de l'environnement sur le dimensionnement. PhD thesis, Mines-ParisTech, France.

620 Nigro, J. and Ishida, H. (1989). Cure behavior of very thin epoxy resin films on steel. Journal of Applied Polymer Science, 38(12):2191-2204.

Roche, A. A. and Guillemenet, J. (1999). Mechanical and chemical properties of organic coatings applied to metallic sheet substrates. The Journal of Adhesion, 342(1-2):52-60.

Safavi-Ardebili, V., Sinclair, A. N., and spelt, J. K. (1997). Experimental Investigation of the Interphase in an Epoxy-Aluminium System. The Journal of Adhesion, 62(1-4):93-111.

Saï, K., Laiarinandrasana, L., Ben Naceur, I., Besson, J., and Cailletaud, G. (2011). Multimechanism damage-plasticity model for semi-crystalline polymer: Creep damage of notched specimen of PA6. Materials Science and Engineering: A, 528(3):1087-1093.

Tadmor, Z. (1974). Molecular orientation in injection molding. Journal of Applied Polymer Science, 18(6):1753-1772.

Talreja, R. (1985). A continuum mechanics characterization of damage in composite materials. In Proceedings of the Royal Society of London.

Thionnet, A. (2010). From Fracture to Damage Mechanics: A behavior law for microcracked composites using the concept of Crack Opening Mode. Composite Structures, 92(3):780-794.

635 Thionnet, A. and Martin, C. (2006). A new constructive method using the theory of invariants to obtain material behavior laws. International Journal of Solids and Structures, 43(2):325-345.

Thionnet, A. and Renard, J. (1993). Meso-macro approach to transverse cracking in laminated composites using Talreja's model. Composites Engineering, 3(9):851-871.

Thionnet, A. and Renard, J. (1999). Modelling unilateral damage effect in strongly anisotropic materials by the introduction of the loading mode in damage mechanics. International Journal of Solids and Structures, 36(28):4269-4287. 